\title{
Freehand thoracic pedicle screw technique using a uniform entry point and sagittal trajectory for all levels: preliminary clinical experience
}

\section{Clinical article}

\author{
Vernard S. Fennell, M.D., Sheri Palejwala, M.D., Jesse Skoch, M.D., \\ David A. STidd, M.D., M.S., and Ali A. BaAJ, M.D. \\ Division of Neurosurgery, University of Arizona Medical Center, Tucson, Arizona
}

\begin{abstract}
Object. Experience with freehand thoracic pedicle screw placement is well described in the literature. Published techniques rely on various starting points and trajectories for each level or segment of the thoracic spine. Furthermore, few studies provide specific guidance on sagittal and axial trajectories. The goal of this study was to propose a uniform entry point and sagittal trajectory for all thoracic levels during freehand pedicle screw placement and determine the accuracy of this technique.

Methods. The authors retrospectively reviewed postoperative CT scans of 33 consecutive patients who underwent open, freehand thoracic pedicle-screw fixation using a uniform entry point and sagittal trajectory for all levels. The same entry point for each level was defined as a point $3 \mathrm{~mm}$ caudal to the junction of the transverse process and the lateral margin of the superior articulating process, and the sagittal trajectory was always orthogonal to the dorsal curvature of the spine at that level. The medial angulation (axial trajectory) was approximately $30^{\circ}$ at T- 1 and T-2, and $20^{\circ}$ from T-3 to T-12. Breach was defined as greater than $25 \%$ of the screw diameter residing outside of the pedicle or vertebral body.

Results. A total of 219 thoracic pedicle screws were placed with a $96 \%$ accuracy rate. There were no medial breaches and 9 minor lateral breaches $(4.1 \%)$. None of the screws had to be repositioned postoperatively, and there were no neurovascular complications associated with the breaches.

Conclusions. It is feasible to place freehand thoracic pedicle screws using a uniform entry point and sagittal trajectory for all levels. The entry point does not have to be adjusted for each level as reported in existing studies, although this technique was not tested in severe scoliotic spines. While other techniques are effective and widely used, this particular method provides more specific parameters and may be easier to learn, teach, and adopt. (http://thejns.org/doi/abs/10.3171/2014.7.SPINE1489)
\end{abstract}

\section{KEY WORDS - thoracic pedicle screw - thoracic fusion - freehand technique}

$\mathrm{P}$ EDICLE screw fixation has become the prevailing modality for thoracic spinal stabilization. ${ }^{18,23,24,26,30,32,36,37}$ Several techniques have been used to increase the ease and accuracy of pedicle screw placement, including the use of intraoperative fluoroscopy, intraoperative CT, and image-assisted navigation. ${ }^{1,3,5,8,39}$ Radiation exposure and its deleterious effects, however, is a growing concern. ${ }^{28,37,39}$ A safe, reproducible, and reliable practice of freehand thoracic screw placement is ideal for reducing intraoperative radiation exposure, reducing the overall operative time, and streamlining the teaching process for surgical trainees. . $^{410,16,19,28,37}$

Existing techniques of freehand pedicle screw place- ment in the thoracic spine primarily focus on various entry points and medial angulation. ${ }^{10,16,20,22}$ Furthermore, no consistent methods to determine cranial-caudal trajectories are described. We believe that existing published techniques and "thoracic pedicle screw charts" may be cumbersome to adopt and teach given the variability of starting points and angulations. To the best of our knowledge, this preliminary study represents one of the few single-surgeon clinical experiences of thoracic pedicle screw placement using a freehand technique that employs a uniform entry point and sagittal trajectory for all thoracic levels. In addition, very simple yet effective axial trajectories are proposed. 


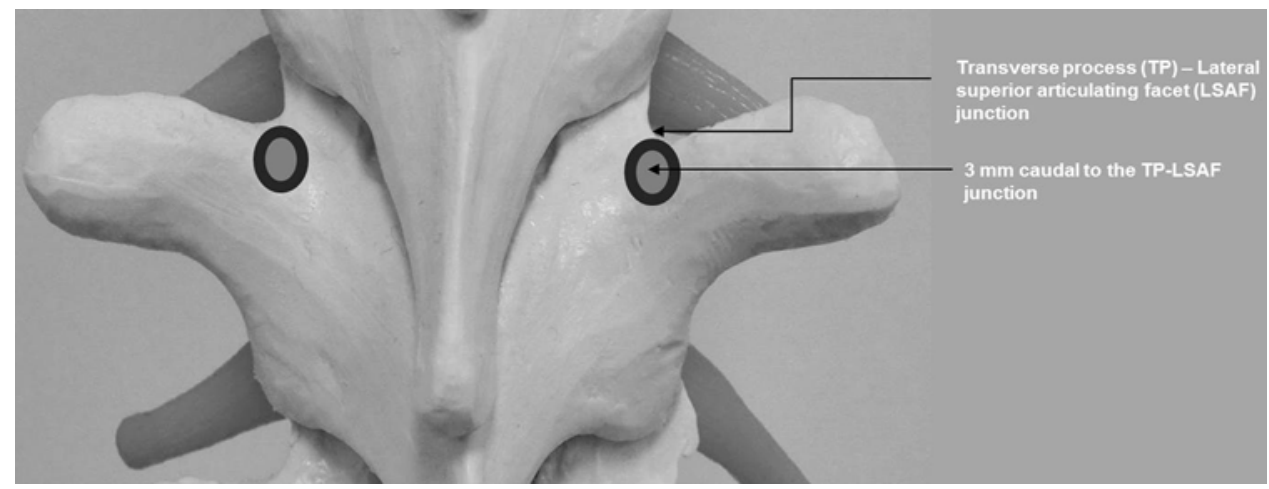

FIG. 1. Illustration demonstrating the uniform entry point, which is always $3 \mathrm{~mm}$ caudal to the junction of the lateral margin of the superior articulating process and the transverse process.

\section{Methods}

We retrospectively reviewed the postoperative CT scans of 33 consecutive patients undergoing open thoracic pedicle screw placement. All cases were performed by the senior author (A.A.B.) and all involved neurosurgical residents assisting with pedicle screw placement under direct supervision. Pedicle screws were placed using a uniform entry point of $3 \mathrm{~mm}$ caudal to the junction of the lateral margin of the superior articulating process and transverse process (Fig. 1). The sagittal trajectory was orthogonal to the curvature of the dorsal spine at that level, which allows a "straight-forward" trajectory of pedicle screw insertion.

After exposure, a high-speed electric drill is used to disrupt the cortical bone at the entry point described above. A sharp, straight gearshift is used to cannulate the pedicle to the desired depth based on preoperative CT measurements. A ball-ended feeler is used to assess for breaches. The pedicle is then typically undertapped and an appropriate size screw is placed. Markers are not used, and we believe that the often-used practice of initial cannulation to $10-15 \mathrm{~mm}$ followed by probing and then completing the cannulation is unnecessary and increases operative time.

Intraoperative fluoroscopy is used for initial localization, and then again for a final anteroposterior and lateral radiograph. Postoperative CT scans were obtained in all patients after thoracic pedicle screw instrumentation. In this study, we retrospectively measured the average medial angulation of all screws that had an acceptable gantry. Computed tomography scans were independently reviewed for breaches by 2 resident physicians (V.S.F. and S.P.), and breach was defined as $>25 \%$ of the screw lying outside of the pedicle.

\section{Results}

Two hundred nineteen consecutive screws were evaluated and no screws were excluded. Screws were placed for a variety of spinal pathology: $61 \%$ for trauma, $12 \%$ for infection, $18 \%$ for tumor, and $9 \%$ for deformity (Fig. 2). The screw distribution was as follows: 23 screws $(10.5 \%)$ at $\mathrm{T}-1,27(12.3 \%)$ at T-2, $11(5 \%)$ at $\mathrm{T}-3,13(5.9 \%)$ at T-4, $10(4.6 \%)$ at T-5, $8(3.7 \%)$ at T-6, $15(6.8 \%)$ at T-7,
$23(10.5 \%)$ at T-8, 23 at T-9 (10.5\%), $25(11.4 \%)$ at T-10, $19(8.7 \%)$ at T-11, and $22(10 \%)$ at T-12 (Fig. 3). There were 9 total lateral breaches (4.1\%; Fig. 4) and no medial breaches. There was no evidence of suprapedicular or infrapedicular breaches. There were no neurovascular- or hardware-related complications, and no instrumentation had to be revised. Medial angulation was measured postoperatively and was, on average, $30^{\circ}$ at $\mathrm{T}-1$ and $\mathrm{T}-2$ and $20^{\circ}$ from T-3 to T-12 (Fig. 5).

\section{Discussion}

Pedicle screw stabilization is now the preferred modality of fixation for thoracolumbar pathologies such as degenerative spine disease, tumor, trauma, and deformity. ${ }^{21,25,32}$ Pedicle screw placement, however, can be challenging, particularly in the thoracic spine. ${ }^{17,19,21,37}$ In this region, the pedicles are typically smaller and have more complex morphologies, thus increasing the risk of malpositioned screws. ${ }^{17,19,21,37}$ The clinical consequences of

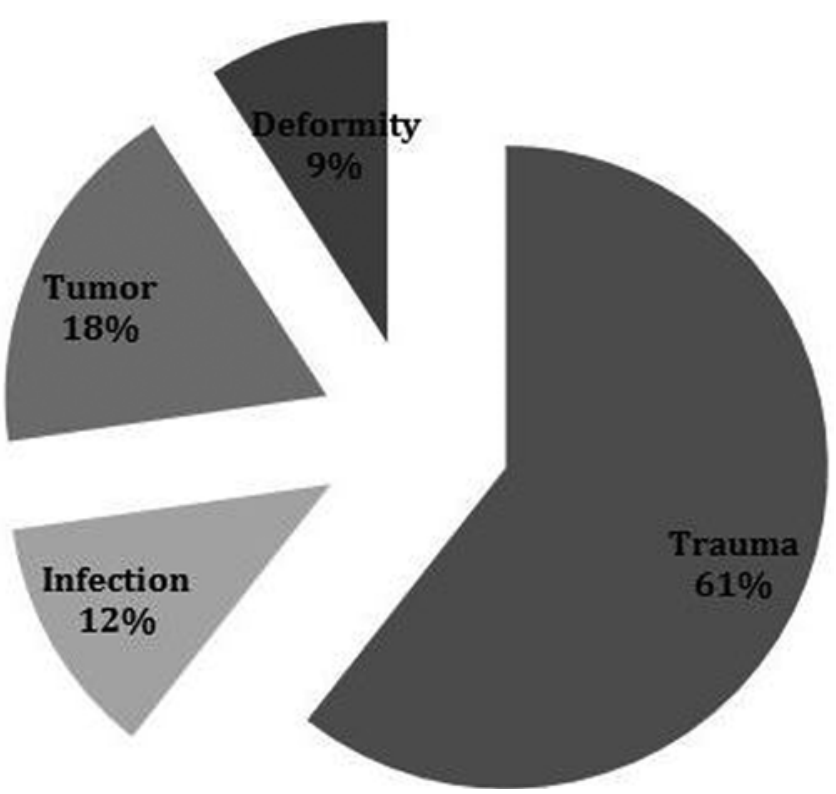

FIG. 2. Distribution of cases with freehand thoracic pedicle screw placement according to spinal pathology. 


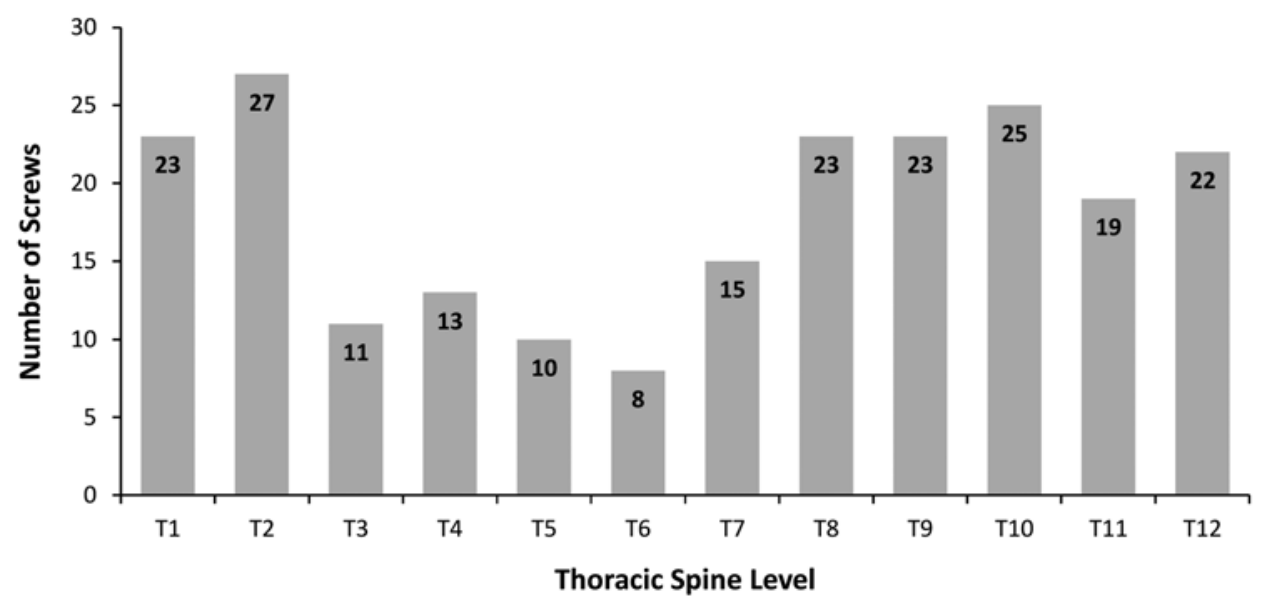

FIG. 3. Distribution of the number of screws placed at each thoracic level.

malpositioned screws can result in neurological, vascular, and visceral organ injuries. ${ }^{17,19,21,37}$

To aid with successful placement of thoracic pedicle screws, intraoperative fluoroscopy and stereotacticguided techniques have gained popularity. ${ }^{1,6,11,15,38}$ These modalities have been associated with increased operative time and radiation exposure to both the patient and the surgeon. ${ }^{6,28}$ This radiation exposure is not without risk, especially for surgeons who perform numerous surgeries over the course of a career. ${ }^{6,28}$ The relative accuracy rates are comparable in fluoroscopically guided versus freehand thoracic pedicle screws. . $^{1,6,8,13,29,33,34}$ In a 2012 review by Gelalis et al., the authors reviewed prospective studies comparing the accuracy rates of freehand, fluoroscopic, and image-guided techniques. ${ }^{13}$ The review included 26 clinical studies, 1105 patients, and 6617 screws. Freehand and fluoroscopy-aided screws had accuracy rates of $69 \%-94 \%$ and $28 \%-85 \%$, respectively, whereas CT- and fluoroscopy-based navigation showed accuracy rates of $89 \%-100 \%$ and $81 \%-92 \%$, respectively. It was noted that

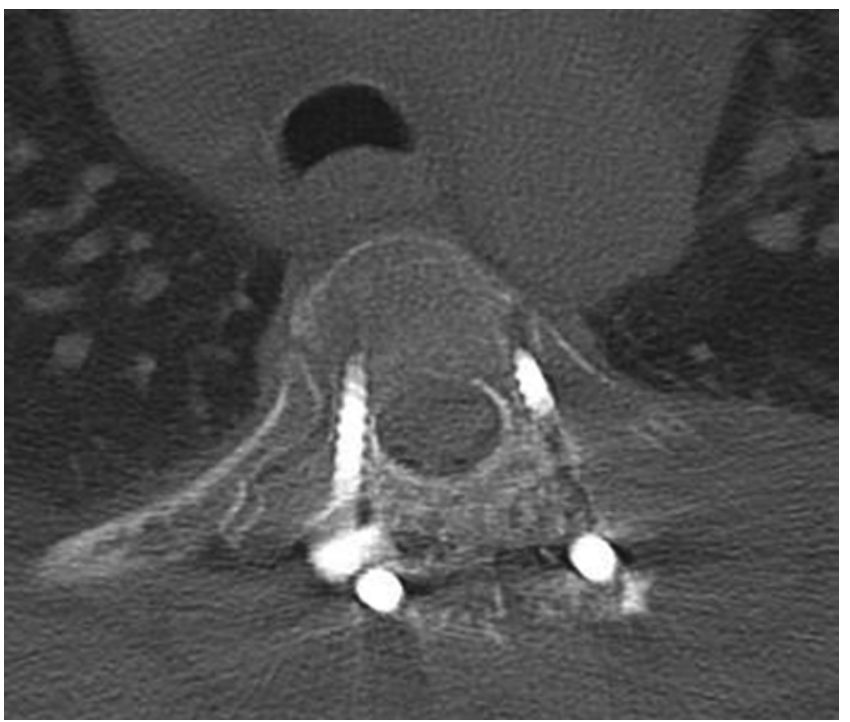

Fig. 4. Example of a lateral breach in which more than $25 \%$ of the pedicle screw is outside the pedicle. perforated screws inserted using the freehand technique tended to be medial, as opposed to lateral with CT navigation.

Temporal limitations and increased radiation exposure associated with the use of intraoperative fluoroscopy and stereotactic navigation have placed an emphasis on the use of freehand techniques. ${ }^{27}$ Technical studies on the use of freehand pedicle screw placement in the thoracic spine are few and limited.,7,19,20,25 Kim and Lenke had one of the first studies to describe the use of the freehand technique for thoracic pedicle screws. ${ }^{18}$ They described a stepwise procedure for the placement of thoracic pedicle screws, starting at the base of the superior articular facet. ${ }^{18}$ Modi et al. confirmed this entry point in their study of patients with scoliosis. ${ }^{25}$ These studies, however, rely almost exclusively on tactile feedback from a pedicle probe to guide both the medial-lateral and cephalad-caudad trajectories. ${ }^{4,7,18,20,25}$ Tactile feedback, however, can be prone to error. ${ }^{14,21}$ While the base of the superior articular facet is generally considered to be the best starting point for pedicle entry, the exact medial-lateral angles and cephalad-caudal trajectories remain subject to surgeon preference. Furthermore, many suggest using the transverse process as an anatomical landmark for freehand
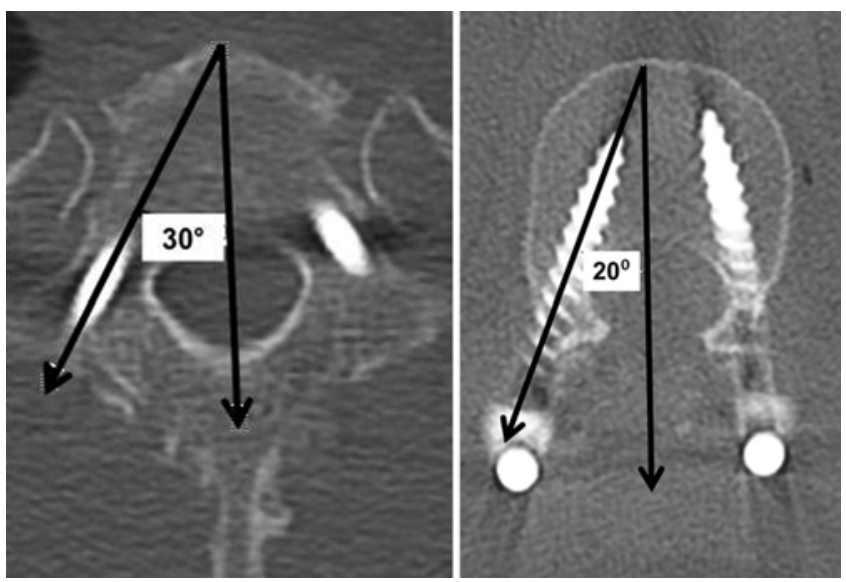

Fig. 5. Axial CT scans demonstrating the mean axial trajectory of a T-2 screw (left) and the mean axial trajectory of a T-12 screw (right). 
Freehand thoracic pedicle screw technique

TABLE 1: Studies of freehand thoracic screw techniques

\begin{tabular}{|c|c|c|c|}
\hline \multirow[b]{2}{*}{ Authors \& Year } & \multirow[b]{2}{*}{$\begin{array}{l}\text { Freehand } \\
\text { Thoracic Screws }\end{array}$} & \multicolumn{2}{|c|}{ Comments } \\
\hline & & Strengths & Weaknesses \\
\hline $\begin{array}{l}\text { Fennell et al. (current } \\
\text { study) }\end{array}$ & 219 & $\begin{array}{l}\text { single surgeon experience, specific \& uniform entry } \\
\text { point, sagittal \& axial trajectories well defined, } \\
\text { low breach rate }\end{array}$ & small series, not tested yet in scoliosis \\
\hline Parker et al., 2011 & 3443 & large series, low breach rates & $\begin{array}{l}\text { complex triangular entry point, sagittal trajectory based } \\
\text { on suboptimally visualized endplate, no axial trajec- } \\
\text { tory guidelines }\end{array}$ \\
\hline Samdani et al., 2010 & 856 & $\begin{array}{l}\text { large series, specific pathology (adolescent idio- } \\
\text { pathic scoliosis) }\end{array}$ & no technique specifics provided \\
\hline Cui et al., 2012 & 404 & large series, specific pathology (scoliosis) & no technique specifics \\
\hline Modi et al., 2009 & 482 & $\begin{array}{l}\text { large series, defined pathology (scoliosis), defined } \\
\text { entry point }\end{array}$ & no guidelines for sagittal or axial trajectories \\
\hline Beck et al., 2009 & 194 & defined entry point & no guidelines for sagittal or axial trajectories \\
\hline Karapinar et al., 2008 & 297 & defined entry point & $\begin{array}{l}\text { thoracic screws T10-12 only, no objective sagittal or } \\
\text { medial trajectories provided }\end{array}$ \\
\hline Upendra et al., 2008 & 314 & compared scoliotic to nonscoliotic spines & $\begin{array}{l}\text { no specifics on technique of entry point, sagittal or } \\
\text { medial trajectories }\end{array}$ \\
\hline Kim et al., 2004 & 3204 & large series, both scoliosis \& kyphosis cases & $\begin{array}{l}\text { entry point varied by level, no sagittal or axial trajecto- } \\
\text { ries provided }\end{array}$ \\
\hline Belmont et al., 2001 & 279 & entry point \& axial trajectories defined & no sagittal trajectories defined \\
\hline
\end{tabular}

placement, but McCormack et al. demonstrated that the transverse process is not as reliable in the thoracic spine relative to the lumbar spine. ${ }^{24}$ In addition, these studies had not provided reliable methods to determine the sagittal trajectories or quantitative medial angulations (Table 1). Another difference between these original studies and our technique is that we do not use a curved probe that necessitates partial cannulation, and then recannulation after the probe is turned $180^{\circ}$. Although effective, this technique slightly lengthens operative time and is not necessary when a more lateral entry point is chosen.

Parker et al. recently published one of the largest series of freehand pedicle screw cases. ${ }^{27}$ With an impressive number of pedicle screws placed and very low breach rates, the authors concluded that in large volume centers, the freehand technique is safe and effective..$^{9,12,27,33,34} \mathrm{We}$ wholeheartedly agree with that conclusion, and our current study offers a slightly different, but equally effective, approach. We have defined a specific entry point that is uniform throughout the thoracic spine and does not rely on visualization of a complex triangular relationship; it only relies on the junction of the lateral margin of the superior articulating facet and the transverse process. Furthermore, this current study offers simple but specific quantitative medial angulation parameters that complement a surgeon's preference and/or bias. Although the overall breach rate was very low, approximately one-third of all breaches were medial in the Parker et al. study, with 2 cases resulting in significant postoperative lowerextremity motor weakness. ${ }^{27}$ Our entry point, which is inherently lateral, may diminish the chance of a medial breach. Our sagittal plane technique relies on pedicle cannulation that is orthogonal to the curvature of the dorsal spine at that level, which is easier to visualize intraoperatively than the superior endplate of the corresponding vertebral body (Fig. 6); this is particularly effective with kyphotic plane deformities. Lastly, pedicle markers are not used in the presented technique, obviating the need for yet an additional lateral radiograph and a minor increase in operative time. Instead, we rely on the final anteroposterior and lateral radiographs and we have rarely had to remove or reposition a screw intraoperatively after it has been placed. More commonly, a breach or errant trajectory is detected after cannulation but before screw placement.

The present study offers our preliminary experience with a freehand thoracic pedicle-screw placement technique utilizing a uniform entry point and axial and sagittal trajectories. Some argue that, in the upper thoracic spine, the ideal entry point is typically more cranial. In our experience, the proposed entry point $(3 \mathrm{~mm}$ caudal to the junction of the transverse process and lateral margin of the superior articulating process) is still effective in this region as long as a cranial-caudal orthogonal cannulation trajectory is used (Fig. 7). Choosing this seemingly caudal entry point obviates the need to adjust entry points in the lower thoracic spine (Fig. 8). There are certainly larger series in the literature and many of the existing techniques are effective and time tested. Our goal was to simplify and minimize variables while maintaining safety and effectiveness. Less variability can potentially make freehand thoracic pedicle screw placement techniques easier to teach and adopt. We have had initial success with this technique, but the efficacy of this ap- 

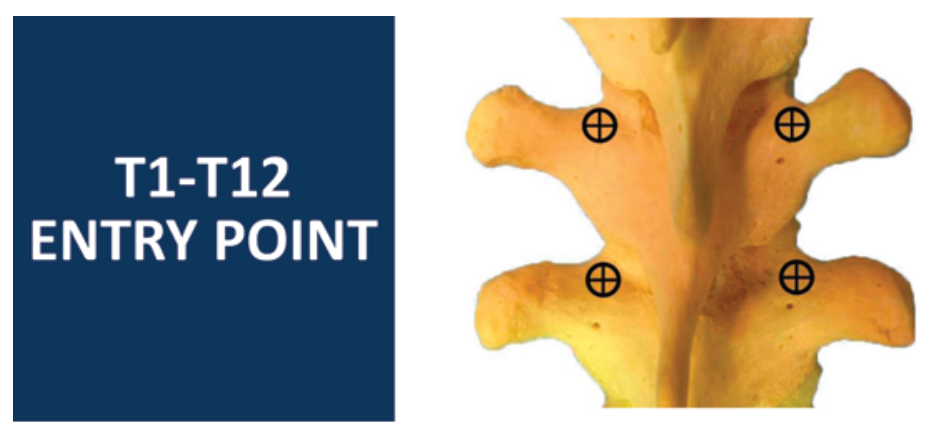

\section{$3 \mathrm{~mm}$ caudal to the junction of the transverse process - superior articulating process}
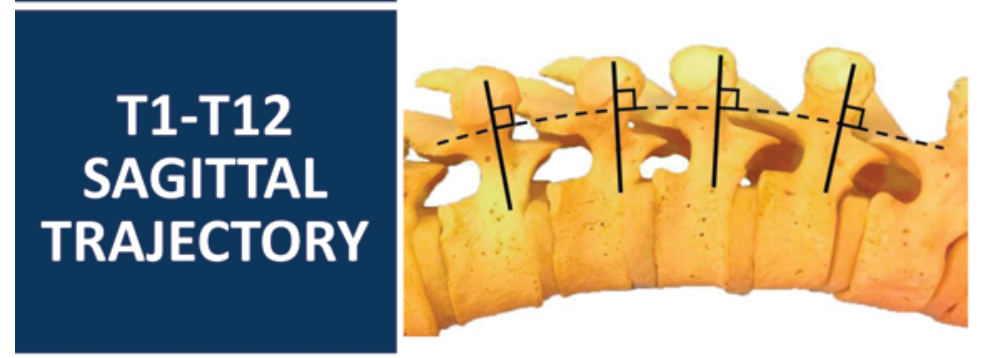

\section{Orthogonal to the sagittal curvature of the dorsal spine}

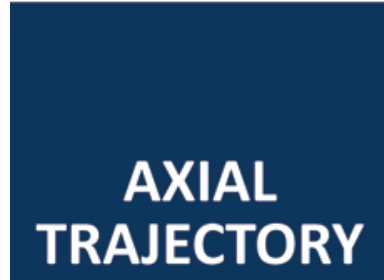

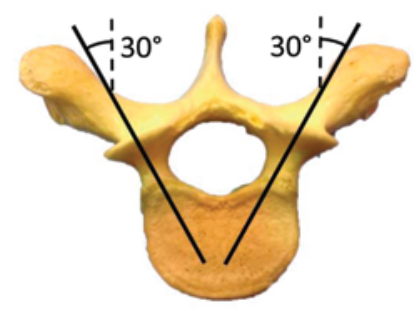

T1-T2

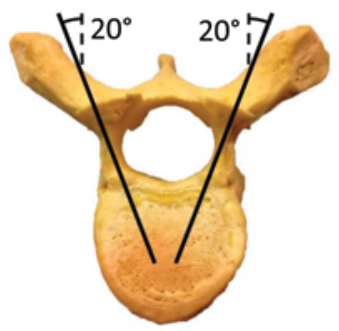

T3-T12

FIG. 6. Freehand thoracic pedicle screw placement chart using a uniform entry point and sagittal trajectory with the appropriate axial trajectory angles. Copyright Ali A Baaj, M.D. Published with permission.

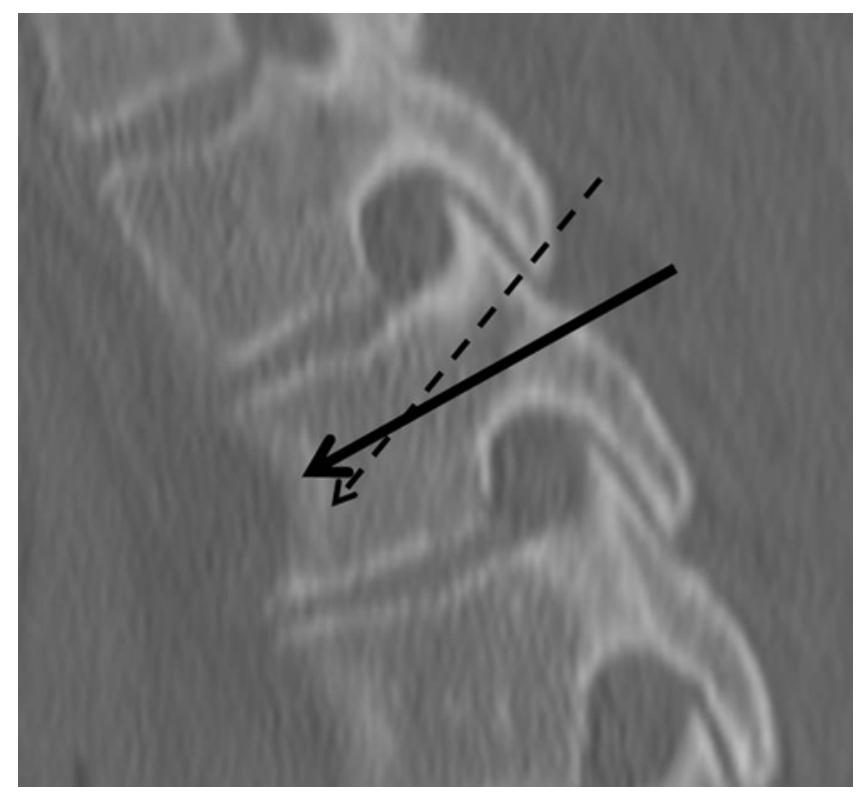

FIG. 7. Parasagittal CT scan of the upper thoracic spine region (T4) demonstrating a traditional entry point and anatomical trajectory (dashed arrow) and a more caudal entry point with straightforward trajectory (solid arrow). Note that effective cannulation of the pedicle is possible, even at this level, with an inferior entry point. proach in scoliotic spines and revision cases has yet to be determined.

As neurosurgeons play a bigger role in complex thoracic instrumentation and deformity cases, the need to acquire an effective and expeditious practice of freehand thoracic pedicle screw placement is imperative to completing these surgeries in a timely fashion. Furthermore, as our exposure to ionizing radiation has increased due to minimally invasive techniques, it is essential that we minimize the use of fluoroscopy in open cases..$^{6,729,37}$

\section{Conclusions}

It is feasible to place freehand thoracic pedicle screws using a uniform entry point and sagittal trajectory for all levels. The entry point does not have to be adjusted for each level as reported in existing studies, although this technique was not tested in severe scoliotic spines. While other techniques are effective and widely employed, this particular method may be easier to learn, teach, and adopt.

\section{Disclosure}

Dr. Baaj has received honoraria from Depuy Synthes, Inc., and Ulrich, Inc., as well as royalties from Thieme Medical Publishers.

Author contributions to the study and manuscript preparation 
Freehand thoracic pedicle screw technique
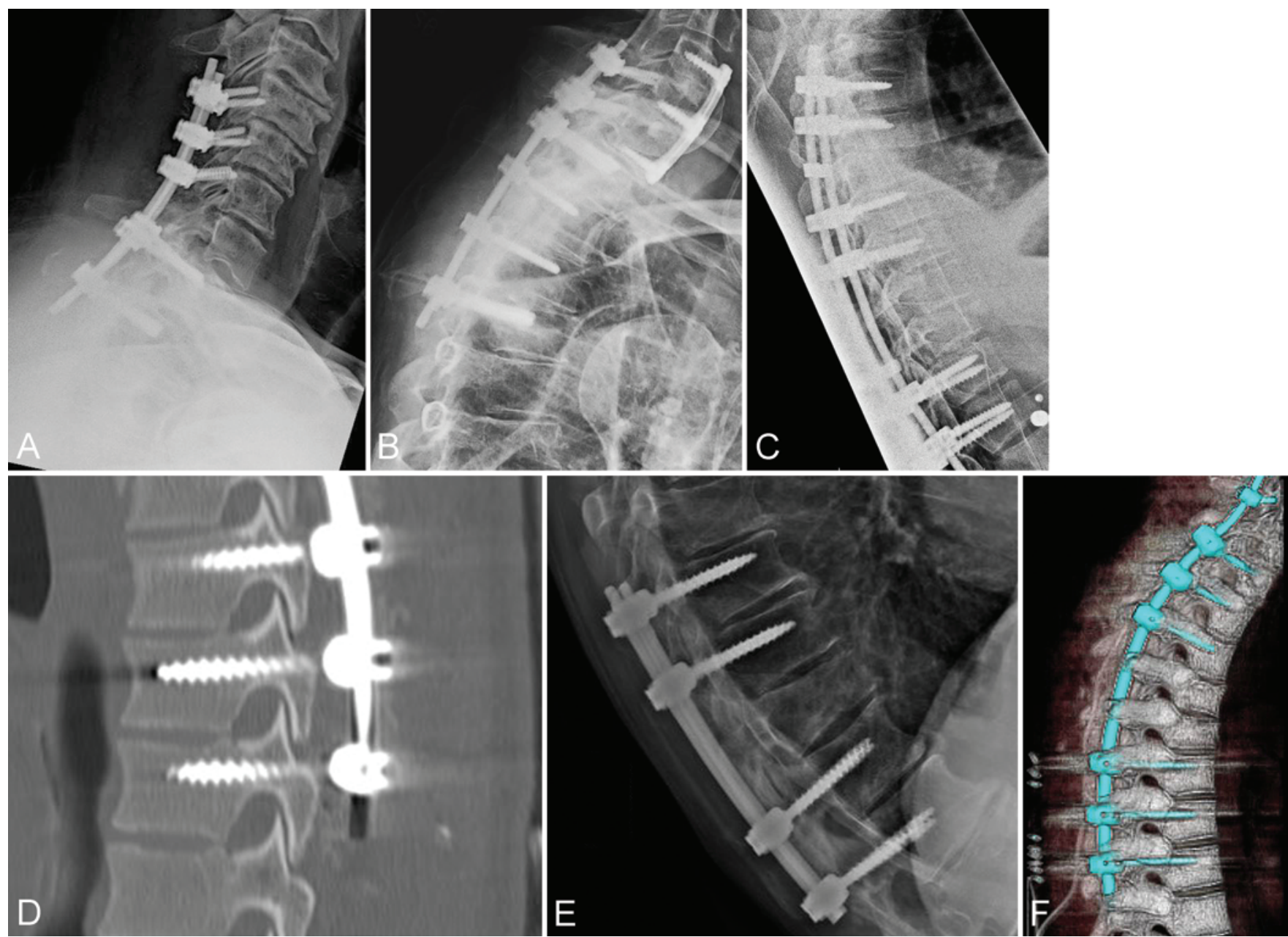

FIG. 8. Multiple CT scans and radiographs demonstrating the feasibility of using our proposed entry point and trajectory at various segments of the thoracic spine; note only thoracic screws from the constructs are highlighted. A: Lateral cervicothoracic radiograph (T-1 and T-2). B: Lateral cervicothoracic radiograph (T1-4). C: Lateral thoracic radiograph (T4-12). D: Sagittal thoracic CT scan (T8-10). E: Lateral thoracolumbar radiograph (T-9, T-10, and T-12). F: Sagittal 3D reconstructed cervicothoracic CT scan showing pedicle screws from T-1 to T-8.

include the following. Conception and design: Baaj. Acquisition of data: Baaj, Fennell, Palejwala. Analysis and interpretation of data: Baaj, Palejwala, Skoch, Stidd. Drafting the article: all authors. Critically revising the article: all authors. Reviewed submitted version of manuscript: all authors. Approved the final version of the manuscript on behalf of all authors: Baaj. Administrative/technical/ material support: Stidd. Study supervision: Baaj.

\section{References}

1. Amiot LP, Lang K, Putzier M, Zippel H, Labelle H: Comparative results between conventional and computer-assisted pedicle screw installation in the thoracic, lumbar, and sacral spine. Spine (Phila Pa 1976) 25:606-614, 2000

2. Beck M, Mittlmeier T, Gierer P, Harms C, Gradl G: Benefit and accuracy of intraoperative 3D-imaging after pedicle screw placement: a prospective study in stabilizing thoracolumbar fractures. Eur Spine J 18:1469-1477, 2009

3. Belmont PJ Jr, Klemme WR, Dhawan A, Polly DW Jr: In vivo accuracy of thoracic pedicle screws. Spine (Phila Pa 1976) 26:2340-2346, 2001

4. Braga BP, de Morais JV, Vilela MD: Free-hand placement of high thoracic pedicle screws with the aid of fluoroscopy: eval- uation of positioning by CT scans in a four-year consecutive series. Arq Neuropsiquiatr 68:390-395, 2010

5. Carbone JJ, Tortolani PJ, Quartararo LG: Fluoroscopically assisted pedicle screw fixation for thoracic and thoracolumbar injuries: technique and short-term complications. Spine (Phila Pa 1976) 28:91-97, 2003

6. Choi WW, Green BA, Levi AD: Computer-assisted fluoroscopic targeting system for pedicle screw insertion. Neurosurgery 47:872-878, 2000

7. Chung KJ, Suh SW, Desai S, Song HR: Ideal entry point for the thoracic pedicle screw during the free hand technique. Int Orthop 32:657-662, 2008

8. Cui G, Wang Y, Kao TH, Zhang Y, Liu Z, Liu B, et al: Application of intraoperative computed tomography with or without navigation system in surgical correction of spinal deformity: a preliminary result of 59 consecutive human cases. Spine (Phila Pa 1976) 37:891-900, 2012

9. El Fiki IM, Zaiton F, Awadalla AM: Role of postoperative multislice computed tomography in assessment of pedicle screw placement in spinal surgical fixation. Egypt J Radiol Nucl Med 44:63-70, 2013

10. Elliott MJ, Slakey JB: Thoracic pedicle screw placement: analysis using anatomical landmarks without image guidance. J Pediatr Orthop 27:582-586, 2007 
11. Fu TS, Chen LH, Wong CB, Lai PL, Tsai TT, Niu CC, et al: Computer-assisted fluoroscopic navigation of pedicle screw insertion: an in vivo feasibility study. Acta Orthop Scand 75: 730-735, 2004

12. Gautschi OP, Schatlo B, Schaller K, Tessitore E: Clinically relevant complications related to pedicle screw placement in thoracolumbar surgery and their management: a literature review of 35,630 pedicle screws. Neurosurg Focus 31(4):E8, 2011

13. Gelalis ID, Paschos NK, Pakos EE, Politis AN, Arnaoutoglou CM, Karageorgos AC, et al: Accuracy of pedicle screw placement: a systematic review of prospective in vivo studies comparing free hand, fluoroscopy guidance and navigation techniques. Eur Spine J 21:247-255, 2012

14. Gertzbein SD, Robbins SE: Accuracy of pedicular screw placement in vivo. Spine (Phila Pa 1976) 15:11-14, 1990

15. Holly LT, Foley KT: Three-dimensional fluoroscopy-guided percutaneous thoracolumbar pedicle screw placement. Technical note. J Neurosurg 99 (3 Suppl):324-329, 2003

16. Hyun SJ, Kim YJ, Cheh G, Yoon SH, Rhim SC: Free hand pedicle screw placement in the thoracic spine without any radiographic guidance: technical note, a cadaveric study. J Korean Neurosurg Soc 51:66-70, 2012

17. Karapinar L, Erel N, Ozturk H, Altay T, Kaya A: Pedicle screw placement with a free hand technique in thoracolumbar spine: is it safe? J Spinal Disord Tech 21:63-67, 2008

18. Kim YJ, Lenke LG: Thoracic pedicle screw placement: freehand technique. Neurol India 53:512-519, 2005

19. Kim YJ, Lenke LG, Bridwell KH, Cho YS, Riew KD: Free hand pedicle screw placement in the thoracic spine: is it safe? Spine (Phila Pa 1976) 29:333-342, 2004

20. Kim YW, Lenke LG, Kim YJ, Bridwell KH, Kim YB, Watanabe K, et al: Free-hand pedicle screw placement during revision spinal surgery: analysis of 552 screws. Spine (Phila Pa 1976) 33:1141-1148, 2008

21. Kosmopoulos V, Schizas C: Pedicle screw placement accuracy: a meta-analysis. Spine (Phila Pa 1976) 32:E111-E120, 2007

22. Lehman RA Jr, Polly DW Jr, Kuklo TR, Cunningham B, Kirk KL, Belmont PJ Jr: Straight-forward versus anatomic trajectory technique of thoracic pedicle screw fixation: a biomechanical analysis. Spine (Phila Pa 1976) 28:2058-2065, 2003

23. Lifeso RM, Arabie KM, Kadhi SK: Fractures of the thoracolumbar spine. Paraplegia 23:207-224, 1985

24. McCormack BM, Benzel EC, Adams MS, Baldwin NG, Rupp FW, Maher DJ: Anatomy of the thoracic pedicle. Neurosurgery 37:303-308, 1995

25. Modi H, Suh SW, Song HR, Yang JH: Accuracy of thoracic pedicle screw placement in scoliosis using the ideal pedicle entry point during the freehand technique. Int Orthop 33:469475, 2009

26. Moon MS, Choi WT, Sun DH, Chae JW, Ryu JS, Chang H, et al: Instrumented ligamentotaxis and stabilization of compression and burst fractures of dorsolumbar and mid-lumbar spines. Indian J Orthop 41:346-353, 2007

27. Parker SL, McGirt MJ, Farber SH, Amin AG, Rick AM, Suk I, et al: Accuracy of free-hand pedicle screws in the thoracic and lumbar spine: analysis of 6816 consecutive screws. Neurosurgery 68:170-178, 2011

28. Rampersaud YR, Foley KT, Shen AC, Williams S, Solomito
M: Radiation exposure to the spine surgeon during fluoroscopically assisted pedicle screw insertion. Spine (Phila Pa 1976) 25:2637-2645, 2000

29. Rampersaud YR, Lee KS: Fluoroscopic computer-assisted pedicle screw placement through a mature fusion mass: an assessment of 24 consecutive cases with independent analysis of computed tomography and clinical data. Spine (Phila Pa 1976) 32:217-222, 2007

30. Roy-Camille R, Saillant G, Berteaux D, Salgado V: Osteosynthesis of thoraco-lumbar spine fractures with metal plates screwed through the vertebral pedicles. Reconstr Surg Traumatol 15:2-16, 1976

31. Samdani AF, Ranade A, Sciubba DM, Cahill PJ, Antonacci MD, Clements DH, et al: Accuracy of free-hand placement of thoracic pedicle screws in adolescent idiopathic scoliosis: how much of a difference does surgeon experience make? Eur Spine J 19:91-95, 2010

32. Şarlak AY, Tosun B, Atmaca H, Sarisoy HT, Buluç L: Evaluation of thoracic pedicle screw placement in adolescent idiopathic scoliosis. Eur Spine J 18:1892-1897, 2009

33. Sclafani JA, Regev GJ, Webb J, Garfin SR, Kim CW: Use of a quantitative pedicle screw accuracy system to assess new technology: initial studies on $\mathrm{O}$-arm navigation and its effect on the learning curve of percutaneous pedicle screw insertion. SAS J 5:57-62, 2011

34. Shin BJ, James AR, Njoku IU, Härtl R: Pedicle screw navigation: a systematic review and meta-analysis of perforation risk for computer-navigated versus freehand insertion. A review. J Neurosurg Spine 17:113-122, 2012

35. Upendra BN, Meena D, Chowdhury B, Ahmad A, Jayaswal A: Outcome-based classification for assessment of thoracic pedicular screw placement. Spine (Phila Pa 1976) 33:384-390, 2008

36. Weinstein JN, Rydevik BL, Rauschning W: Anatomic and technical considerations of pedicle screw fixation. Clin Orthop Relat Res (284):34-46, 1992

37. Weinstein JN, Spratt KF, Spengler D, Brick C, Reid S: Spinal pedicle fixation: reliability and validity of roentgenogrambased assessment and surgical factors on successful screw placement. Spine (Phila Pa 1976) 13:1012-1018, 1988

38. Youkilis AS, Quint DJ, McGillicuddy JE, Papadopoulos SM: Stereotactic navigation for placement of pedicle screws in the thoracic spine. Neurosurgery 48:771-779, 2001

39. Zhang C, Wang Z, Zhang C, Chen F, Zhang H, Yan X: Spine Bull's-Eye Robot guidewire placement with pedicle standard axis view for thoracic and lumbar pedicle screw fixation. J Spinal Disord Tech 25:E191-E198, 2012

Manuscript submitted January 24, 2014.

Accepted July 14, 2014.

Please include this information when citing this paper: published online August 22, 2014; DOI: 10.3171/2014.7.SPINE1489.

Address correspondence to: Ali A. Baaj, M.D., Division of Neurosurgery, University of Arizona Medical Center, 1501 N. Campbell Ave., P.O. Box 245070, Tucson, AZ 85724. email: abaaj@surgery. arizona.edu. 